\title{
Missed opportunities to diagnose syphilis prior to the development of sight-losing uveitis
}

\author{
JD Widdrington ${ }^{1}$, I Ashfaq ${ }^{2}$, B Puvaneswaran ${ }^{3}$, EL Ong $^{4}$, U Schwab $^{5}$, DA Price $^{6}$, ML Schmid $^{7}$, R Pandit $^{8}$
}

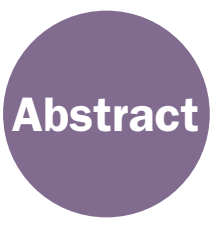

The incidence of syphilis in the UK is rapidly rising. Uveitis (intraocular inflammation) usually occurs in the secondary or later stages of syphilis infection and is sight-threatening.

Methods A retrospective analysis of the demographics, presentation, diagnosis, treatment and outcomes of patients with syphilitic uveitis managed in Newcastle from 2005-2016 was carried out.

Results Ten males (19 eyes) with syphilitic uveitis had a generally good visual and serological response to penicillin treatment. In eight of the patients there had been a failure to test for syphilis during assessments by various medical practitioners for unexplained symptoms that were attributable to syphilis prior to the eye involvement.

\author{
Correspondence to: \\ $J$ Widdrington \\ Department of Infection \\ and Tropical Medicine \\ Royal Victoria Infirmary \\ Newcastle upon Tyne \\ NE1 4LP \\ UK
}

Email: john.widdrington@ newcastle.ac.uk

Conclusion Uveitis associated with syphilis can be sight-threatening but responds well to treatment. In our case series there were multiple missed opportunities to diagnose syphilis prior to presentation with eye disease, with a general failure of healthcare professionals to take an adequate sexual history.

Keywords: delayed, diagnosis, syphilis, treatment, uveitis

Declaration of interests: No conflict of interests declared

\section{Background}

Syphilis is a multisystem infection due to the sexual or vertical transmission of the spirochete Treponema pallidum. There are four stages of sexually-acquired syphilis which have distinct clinical features and require different treatment regimens (Table 1). Ocular involvement may occur at any stage of infection, but most usually in the secondary or later stages, and results in uveitis (intraocular inflammation) which, in keeping with the other manifestations of syphilis, has a very variable presentation. ${ }^{1}$ In view of this, it is recommended that almost all patients with new onset uveitis should be tested for syphilis, unless the cause of uveitis is immediately apparent, such as typical human leukocyte antigen-B27associated recurrent iritis. ${ }^{2}$ Treponema pallidum remains very sensitive to treatment with penicillin and, in general, patients with ocular syphilis can expect to have a good response to the treatment protocols for neurosyphilis that are mandated in the British, European and American guidelines. ${ }^{3-5}$

Following a dramatic decline due to the introduction of penicillin treatment, in recent years there has been a significant and consistent increase in the incidence of syphilis in the USA and Western Europe, particularly in men who have sex with men (MSM). ${ }^{4,6}$ In 2015 there were 5,288 cases of syphilis in the UK, representing a 76\% increase since 2012; 4,192 (79\%) of these cases were in MSM in whom cases have increased by $95 \%$ since $2012 .^{7}$ Although data on ocular syphilis are less available, an epidemic of cases in Seattle and San Francisco in 2015 led to the Centers for Disease Control and Prevention issuing a clinical advisory warning to promote the recognition and correct management of ocular syphilis in the USA. ${ }^{8}$

We present our review of the cases of syphilitic uveitis managed by the medical ophthalmology and infectious diseases departments at the Newcastle upon Tyne Hospitals NHS Foundation Trust, in the past 11 years. We found there was a significant delay in the diagnosis of syphilis, with multiple missed opportunities to test syphilis serology, in the majority of patients ultimately presenting with ocular syphilis. Clinical outcomes were generally good after treatment.

\section{Methods}

This was a retrospective analysis of the presentation and management of patients treated for syphilitic uveitis between 2005 and 2016 at the Newcastle upon Tyne Hospitals NHS

\footnotetext{
1,3Specialty Trainees, Department of Infection and Tropical Medicine; ${ }^{2}$ Retinal fellow, Department of Ophthalmology; ${ }^{3,4,5,6} \mathrm{Consultants,}$ Department of Infection and Tropical Medicine; ${ }^{4}$ Consultant, Department of Ophthalmology, Newcastle upon Tyne Hospitals NHS Foundation Trust, UK
} 
Table 1 Clinical stages of syphilis ${ }^{5}$

\begin{tabular}{lll} 
Clinical stage & Timing & Clinical features \\
\hline Primary & $\begin{array}{l}\text { Incubation period } \\
\text { 21 days, lasts 3-8 } \\
\text { weeks }\end{array}$ & Painless ulcer (chancre) \\
\hline Secondary & $\begin{array}{l}\text { 4-10 weeks later, } \\
\text { lasts 3-12 weeks }\end{array}$ & $\begin{array}{l}\text { Multisystem disease - rash (classically involving palms and soles), alopecia, } \\
\text { mucous ulcers, condylomata lata, splenomegaly, lymphadenopathy and fevers }\end{array}$ \\
\hline Latent & Early $<2$ years & Asymptomatic \\
& Late $>$ 2 years & \\
\hline Tertiary & Several years later & $\begin{array}{l}\text { 1. Gummatous - skin and bone granulomas } \\
\text { 2. Cardiovascular - aortitis } \\
\text { 3. Neurological - meningovascular (stroke) or parenchymous (generalised paresis } \\
\text { or tabes dorsalis) }\end{array}$ \\
& &
\end{tabular}

a

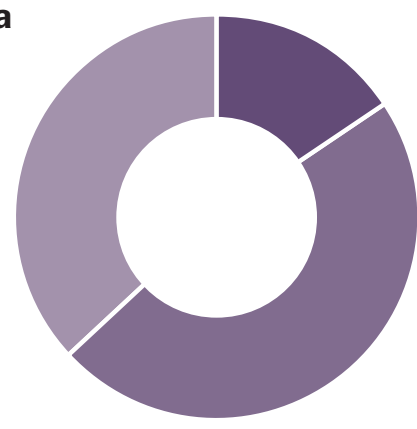

- Anterior and/or Intermediate Uveitis

- Posterior uveitis / chorioretinitis

- Panuveitis

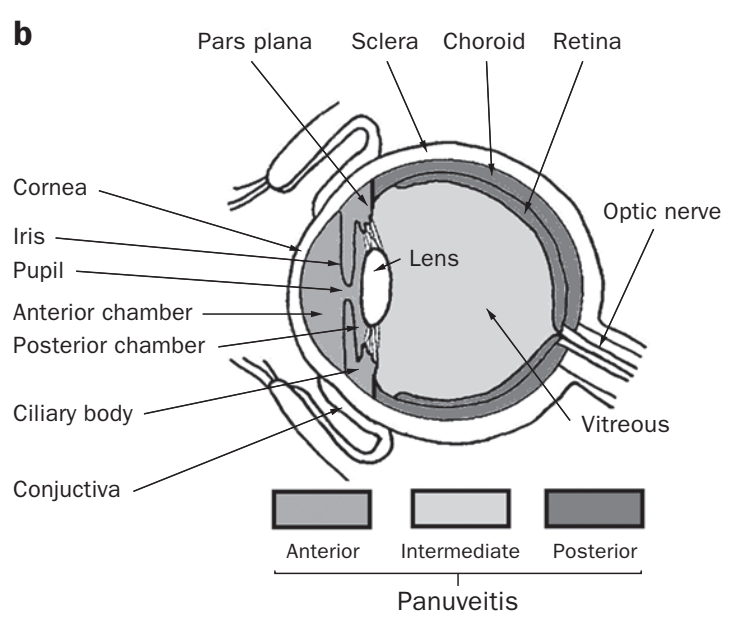

Figure 1 Ocular diagnoses in patients with uveitis due to syphilis. (a) Different diagnostic categories for the 19 eyes affected by syphilitic uveitis. (b) Anatomy of the eye illustrating the different types of uveitis caused by syphilis (adapted from ${ }^{24}$ )
Foundation Trust. The case definition for syphilitic uveitis was an adult patient presenting with uveitis and positive treponemal serology (both treponemal-specific serology and the non-treponemal venereal disease reference laboratory (VDRL) test). Patients were identified from clinical coding and the Newcastle Uveitis Service database. Anonymised details of patient demographics, systemic and ocular presenting features, serological diagnosis, ocular imaging, treatment and serological and visual outcomes were collected. Caldicott approval was granted prior to collection of anonymised data.

\section{Results}

\section{Background features}

Ten male patients (19 eyes, median age 45.5, range 41-70 yrs) with syphilitic uveitis treated in Newcastle between 2005 and 2016 were identified and included in our analysis (Table 2). None had been diagnosed with or treated for syphilis previously. Syphilis was acquired through homosexual intercourse in nine patients and heterosexual intercourse in the remaining patient. One was known to be HIV positive prior to the diagnosis of syphilis and another was diagnosed with HIV during the treatment for syphilis.

There was a delay in the diagnosis of syphilis in eight of the ten patients with a median delay from the development of symptoms consistent with syphilis to presentation with ocular manifestations of 5 months (range 3-9 months). Seven of these eight patients described classical features of secondary syphilis (Table 1) prior to the onset of ocular symptoms, while three patients had pre-existing ocular symptoms. Prior to the diagnosis of syphilitic uveitis, these seven patients had been investigated by clinicians in primary and secondary care for symptoms which are consistent with syphilis infection, but none was tested for syphilis or had evidence that an adequate sexual history was obtained. The two cases discussed below illustrate some of the missed opportunities to diagnose syphilis prior to the presentation with ocular involvement.

\section{Diagnosis and treatment of syphilitic uveitis}

The median duration of ocular symptoms prior to presentation was 9.5 days (range $2-60$ days). All patients complained of decreased vision, four had eye pain and three had red eyes. Nine (90\%) had bilateral eye involvement. The ophthalmic diagnosis was posterior uveitis/chorioretinitis in nine eyes (three of which had acute placoid chorioretinitis, a finding pathognomic of syphilis ${ }^{9}$ ), panuveitis in seven eyes and anterior and/or intermediate uveitis in three eyes (Figure 1). Treponemal-specific serological tests were positive in all ten patients. At presentation the VDRL was detectable in all ten 
Table 2 Clinical details of cases of ocular syphilis managed in Newcastle 2005-2016

\begin{tabular}{|c|c|c|c|c|c|c|c|c|c|c|}
\hline & $\begin{array}{l}\text { Age } \\
\text { (yrs) }\end{array}$ & $\begin{array}{l}\text { HIV } \\
\text { status }\end{array}$ & $\begin{array}{l}\text { Initial } \\
\text { symptoms } \\
\text { to } \\
\text { diagnosis }\end{array}$ & Prior symptoms & $\begin{array}{l}\text { Specialties } \\
\text { investigating } \\
\text { prior } \\
\text { symptoms }\end{array}$ & $\begin{array}{l}\text { Type of } \\
\text { uveitis }\end{array}$ & $\begin{array}{l}\text { Initial } \\
\text { visual } \\
\text { acuity }\end{array}$ & $\begin{array}{l}\text { Initial } \\
\text { VDRL }\end{array}$ & $\begin{array}{l}\text { Final } \\
\text { visual } \\
\text { acuity }\end{array}$ & $\begin{array}{l}\text { Final } \\
\text { VDRL }\end{array}$ \\
\hline A & 57 & Neg & 9 months & $\begin{array}{l}\text { Fevers, } \\
\text { lymphadenopathy } \\
\text { (biopsied) and } \\
\text { maculopapular } \\
\text { rash. Loss of } \\
\text { vision in left eye }\end{array}$ & $\begin{array}{l}\text { Endocrinology, } \\
\text { Haematology }\end{array}$ & $\begin{array}{l}\text { LE } \\
\text { chorioretinitis, } \\
\text { RE placoid } \\
\text { chorioretinitis }\end{array}$ & $\begin{array}{l}\text { RE: } 6 / 6 \text {, } \\
\text { LE: CF }\end{array}$ & $1: 256$ & $\begin{array}{l}\text { RE: } 6 / 6 \text {, } \\
\text { LE: } 6 / 9\end{array}$ & $1: 32$ \\
\hline B & 41 & Pos & 8 months & $\begin{array}{l}\text { Genital ulcer } \\
\text { followed by } \\
\text { palmar rash }\end{array}$ & Dermatology & $\begin{array}{l}\text { Bilateral } \\
\text { chorioretinitis }\end{array}$ & $\begin{array}{l}\text { RE: 6/9, } \\
\text { LE: PL }\end{array}$ & $1: 128$ & $\begin{array}{l}\text { RE: } 6 / 12 \text {, } \\
\text { LE: } 6 / 9\end{array}$ & $1: 32$ \\
\hline C & 47 & Neg & 6 months & Blurred vision & $\mathrm{n} / \mathrm{a}$ & $\begin{array}{l}\text { Bilateral } \\
\text { anterior and } \\
\text { intermediate } \\
\text { uveitis }\end{array}$ & $\begin{array}{l}\text { RE: } 6 / 6 . \\
\text { LE: } 6 / 9\end{array}$ & $1: 128$ & $\begin{array}{l}\text { RE: } 6 / 5 \text {, } \\
\text { LE: } 6 / 9\end{array}$ & $1: 32$ \\
\hline D & 46 & Neg & 8 months & $\begin{array}{l}\text { Night sweats, } \\
\text { evanescent } \\
\text { rash, mouth } \\
\text { ulcer (biopsied } \\
\text { twice), anal } \\
\text { warts (biopsied). } \\
\text { Blurred vision }\end{array}$ & $\begin{array}{l}\text { Colorectal } \\
\text { surgery, ENT, } \\
\text { Oral surgery }\end{array}$ & $\begin{array}{l}\text { RE placoid } \\
\text { chorioretinitis }\end{array}$ & $\begin{array}{l}\text { RE: } 6 / 24 ; \\
\text { LE: } 6 / 9\end{array}$ & $1: 128$ & $\begin{array}{l}\text { RE: } 6 / 12, \\
\text { LE: } 6 / 6\end{array}$ & $\begin{array}{l}\text { Not } \\
\text { done }\end{array}$ \\
\hline$E$ & 45 & Pos & Nil & Nil reported & $n / a$ & $\begin{array}{l}\text { Bilateral } \\
\text { panuveitis, } \\
\text { LE placoid } \\
\text { chorioretinitis }\end{array}$ & $\begin{array}{l}\text { RE: } 6 / 60 \text {, } \\
\text { LE: CF }\end{array}$ & $1: 32$ & $\begin{array}{l}\text { RE: } 6 / 12, \\
\text { LE: } 6 / 12\end{array}$ & $1: 8$ \\
\hline$F$ & 41 & Neg & Nil & Nil reported & $\mathrm{n} / \mathrm{a}$ & $\begin{array}{l}\text { Bilateral } \\
\text { panuveitis }\end{array}$ & $\begin{array}{l}\text { RE: } 6 / 12, \\
\text { RE: } 6 / 9\end{array}$ & $1: 128$ & $\begin{array}{l}\text { RE: } 6 / 9 \text {, } \\
\text { LE } 6 / 9\end{array}$ & $1: 16$ \\
\hline G & 42 & Neg & 3 months & $\begin{array}{l}\text { Weight loss, } \\
\text { alopecia and } \\
\text { lymphadenopathy } \\
\text { (biopsied) }\end{array}$ & $\begin{array}{l}\text { Haematology, } \\
\text { General } \\
\text { surgery }\end{array}$ & $\begin{array}{l}\text { Bilateral } \\
\text { panuveitis }\end{array}$ & $\begin{array}{l}\text { RE: PL, LE: } \\
\text { HM }\end{array}$ & $1: 128$ & $\begin{array}{l}\text { RE: CF, LE: } \\
6 / 36\end{array}$ & $1: 1$ \\
\hline $\mathrm{H}$ & 70 & Neg & 4 months & $\begin{array}{l}\text { Weight loss, } \\
\text { rash, balanitis } \\
\text { (biopsied), } \\
\text { adrenal } \\
\text { insufficiency }\end{array}$ & $\begin{array}{l}\text { Endocrinology, } \\
\text { Urology }\end{array}$ & $\begin{array}{l}\text { RE anterior } \\
\text { uveitis, LE } \\
\text { panuveitis }\end{array}$ & $\begin{array}{l}\text { RE: } 6 / 9 \text {, } \\
\text { LE: PL }\end{array}$ & $>1: 256$ & $\begin{array}{l}\text { RE: } 6 / 9 \text {, } \\
\text { LE: PL }\end{array}$ & $1: 32$ \\
\hline I & 41 & Neg & 3 months & $\begin{array}{l}\text { Fever, } \\
\text { weight loss, } \\
\text { maculopapular } \\
\text { rash and } \\
\text { lymphadenopathy }\end{array}$ & Haematology & $\begin{array}{l}\text { Bilateral } \\
\text { chorioretinitis }\end{array}$ & $\begin{array}{l}\text { RE: } 6 / 60 \text {, } \\
\text { LE: } 6 / 9\end{array}$ & $1 .: 128$ & $\begin{array}{l}\text { RE: } 6 / 12, \\
\text { LE: } 6 / 6\end{array}$ & $\begin{array}{l}\text { Not } \\
\text { done }\end{array}$ \\
\hline J & 65 & Neg & 3 months & $\begin{array}{l}\text { Night sweats, } \\
\text { myalgia, } \\
\text { arthralgia and } \\
\text { maculopapular } \\
\text { rash }\end{array}$ & $\begin{array}{l}\text { General } \\
\text { practitioner }\end{array}$ & $\begin{array}{l}\text { Bilateral } \\
\text { panuveitis }\end{array}$ & $\begin{array}{l}\text { RE: } 6 / 9 \text {, } \\
\text { LE: CF }\end{array}$ & $1: 128$ & $\begin{array}{l}\text { RE: } 6 / 6, \\
\text { LE: } 6 / 18\end{array}$ & $1: 8$ \\
\hline
\end{tabular}

Visual acuity is measured on the Snellen scale. CF, counting fingers; HM, hand movements; LE, left eye; PL, perception of light; RE, right eye; VDRL, venereal diseases reference laboratory

patients with a median titre of 1:128 (range 1:32 to $>1: 256)$. A lumbar puncture was carried out in seven patients (70\%); five showed cerebrospinal fluid evidence of neurosyphilis.

All patients were treated with treponemicidal doses of parenteral penicillin for 17 days in accordance with the
British Association for Sexual Health and HIV guidelines. ${ }^{5}$ In addition, all patients received tapering regimens of topical corticosteroids and mydriatics. Seven (70\%) received systemic corticosteroids with a median starting dose of 50 mg (range 40-60 mg) oral prednisolone, tapered according to the degree of ongoing intraocular inflammation. 
Figure 2 Fundal images before (left) and after (right) treatment for ocular syphilis indicating significant improvement in placoid chorioretinitis in the right eye

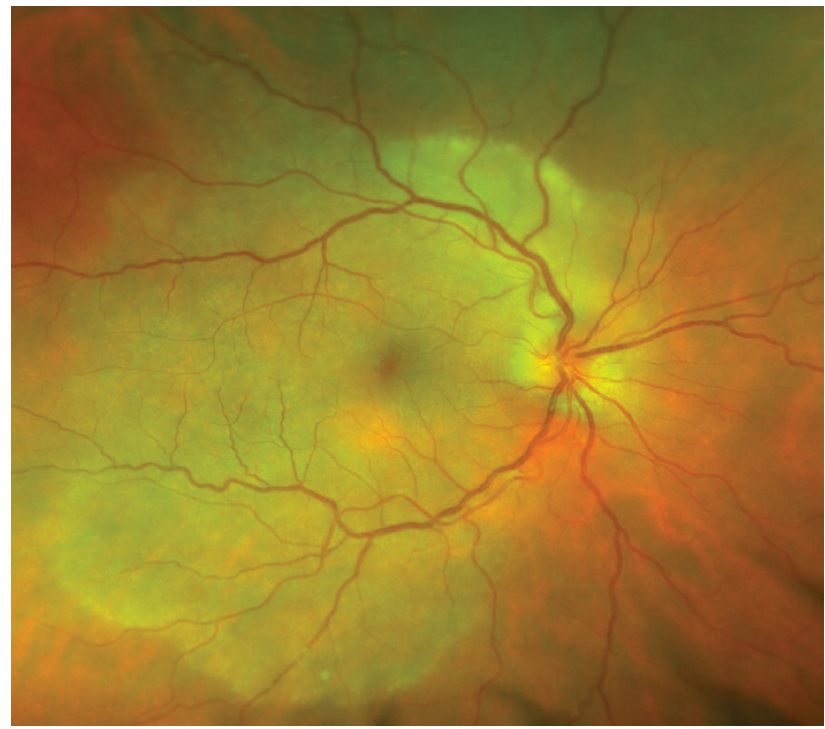

\section{Outcomes}

Treatment of syphilis resulted in resolution of intraocular inflammation and improvement of visual acuity in the majority of patients. Of the 19 affected eyes, visual acuity improved by at least one line on the Snellen chart in 13 eyes, with a median improvement of two lines (range -1 to +8 ) (Table 2). In two eyes, visual acuity deteriorated following treatment, in both cases by one line and in association with an improvement in the acuity in the other eye. There was an improvement in the syphilis serology after treatment, with all eight patients who attended follow-up achieving the target of a four-fold reduction in VDRL titre at 6 months post treatment (median VDRL at 6 months post treatment was 1:32, range $1: 1-1: 32) .^{5}$

\section{Case studies}

\section{Patient 1}

A 46-year-old male presented 4 weeks after a sudden onset of painless loss of vision in his right eye. Examination revealed a right-sided relative afferent pupillary defect with reduced acuity (6/24 Snellen acuity) and colour vision. The right optic disc was swollen and there was a large area of placoid chorioretinitis at the right macula (Figure 2). Syphilis serology was positive with a VDRL titre of 1:128 and he was immediately commenced on a 17 day course of procaine penicillin and probenicid, along with topical and systemic steroids (prednisolone $60 \mathrm{mg}$ for 3 days). At 3 months post treatment he had excellent improvement in his retinal appearance, visual acuity (6/12) and non-treponemal serology tests (VDRL 1:32).

Prior to presentation with ocular symptoms he had an 8-month history of night sweats following a self-resolving evanescent skin rash. During this period he had persistent mouth ulcers which were investigated by both ENT and oral surgeons. On both occasions he had biopsies of the ulcers,

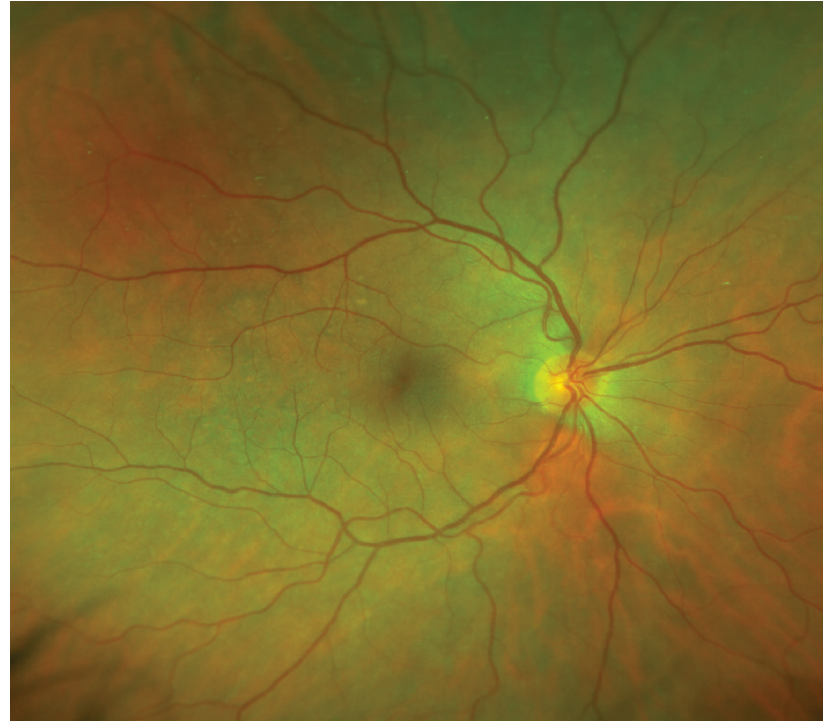

which indicated chronic inflammation attributed to smoking. In addition, he had been troubled by a circumferential anal wart which was extensively investigated by colorectal surgeons. There is no documentation of an adequate sexual history at any of these assessments and at no point was syphilis serology tested.

\section{Patient 2}

A 70-year-old male initially presented after a fall, following a one week history of intermittent dizziness and three months of weight loss. He was thin with hypotension and a patchy scaly rash over his palms with associated hyperpigmentation. Investigations revealed an acute kidney injury with hyponatraemia and hyperkalaemia. A short Synacthen test confirmed adrenal insufficiency and imaging indicated diffusely hypertrophic adrenal glands with retroperitoneal lymphadenopathy. He was reviewed by a urologist who noted a painless erythematous glans penis with associated urethral thickening. A glans biopsy revealed zoon balanitis. His adrenal insufficiency was treated with hydrocortisone, which resulted in symptomatic and biochemical improvement. At no point during this admission was syphilis serology tested. Retrospective history taking revealed that he recalled having unprotected sex with three casual female partners in the months prior to hospital admission.

Two months later he presented to eye casualty with one week history of a red left eye associated with reduced visual acuity (left eye - light perception, right eye - 6/9). Examination revealed bilateral panuveitis. Syphilis serology was positive with a VDRL titre of $>1: 256$. He was immediately commenced on a 17 day course of benzylpenicillin, along with topical corticosteroids and cyclopentolate. Unfortunately, his treatment was complicated by the development of a left total retinal detachment which was inoperable and resulted in blindness of his left eye. 
Box 1 Summary of British Association of Sexual Health and HIV minimum components of a sexual history ${ }^{16}$

\section{Key components of a sexual history components}

- Symptoms of sexually transmitted infection(s) including dysuria, genital discharge, genital ulceration

- Date of last sexual contact

- Total number of partners in the past 3 months

- Gender(s) of partners

- Anatomical sites of exposure - including whether insertive or receptive intercourse

- Condom use

- Clarify any suspected infection risk or symptoms in partner(s)

- Previous history of sexually transmitted infections

- For women - last menstrual period, contraceptive and cervical smear history

- Blood-borne virus risk assessment and vaccination history for those at risk

- Agree the method for communicating results of tests

\section{Discussion}

In this case series we have described ten patients presenting with uveitis as an uncommon but serious manifestation of syphilis. Syphilis can affect all structures of the eye, with the most frequent ocular manifestation being uveitis, which may be unilateral or bilateral. ${ }^{1}$ Uveitis is classified anatomically depending on the predominant location of inflammation inside the eye; anterior (anterior chamber), intermediate (vitreous), posterior (retina and/or choroid, including chorioretinitis) or panuveitis (equal involvement of all three locations) (Figure 1b). ${ }^{10}$ Posterior uveitis or panuveitis from syphilis infection may cause severe sight loss or blindness if untreated, but treatment can dramatically reverse the visual loss, as illustrated in six of our patients (Table 2). ${ }^{1,6}$

Our case series is comparable to that described in the British Ocular Syphilis Study, a national prospective population-based study, which identified 41 patients (63 eyes) with intraocular syphilis between 2009 and 2011. ${ }^{11}$ These patients were predominantly male (90.2\%), 56\% had bilateral disease and panuveitis was the most frequent diagnosis (41.3\%). In agreement with our findings, $92.1 \%$ of these patients had an improvement in visual acuity following penicillin treatment and $48 \%$ of those in which details were recorded described a recent illness with symptoms attributable to syphilis. Other recent case series of syphilitic uveitis from the USA, Australia and China describe a similar picture of predominantly bilateral posterior segment disease in patients with recent symptoms suggestive of primary or secondary syphilis, most of whom achieve good ocular outcomes following penicillin treatment. ${ }^{12-15}$

The incidence of syphilis in the UK is rapidly rising, particularly in the MSM population. ${ }^{7}$ However, the awareness of syphilis in non-specialists is not rising in parallel with this change.
We have identified a clear failure to take an adequate sexual history (Box 1) or consider testing for syphilis in the majority of cases in the months prior to the presentation with eye involvement. ${ }^{16}$

It is well recognised there are a number of barriers to sexual history taking in healthcare professionals, including inadequate communication skills training, a lack of emphasis on sexual health during clinical training and the impact of personal beliefs on professional behaviour. ${ }^{17}$ Furthermore, when non-specialists consider sexually transmitted infections they tend to test in a selective and restrictive manner, rather than adopting the comprehensive testing that is used in genito-urinary medicine clinics. ${ }^{18}$ This is illustrated by the finding that three patients in our series had HIV testing when presenting with unexplained symptoms but syphilis testing was not carried out at the same time.

A number of studies have explored the barriers to testing for HIV and these are likely to be relevant to syphilis given the similar risk factors and stigma surrounding both infections. In 2014 approximately $40 \%$ of patients diagnosed with HIV in the UK already had late-stage disease leading to increased morbidity and mortality. ${ }^{19}$ In a significant proportion of these cases there had been missed opportunities to diagnose HIV in the 12 months prior to diagnosis; in one study $25 \%$ of newly identified HIV positive patients had been seen in a healthcare setting in the past year, $71 \%$ of which were subsequently diagnosed with late-stage HIV infection. ${ }^{20}$ Although individuals may avoid HIV testing due to a failure to recognise they are at risk or fear of the consequences of a positive test, in most cases low levels of testing have been found to be due to low numbers of HIV tests being offered. ${ }^{21,22}$ Reasons for healthcare professionals failing to test for HIV include a perceived lack of knowledge and training about the risk factors and clinical features of HIV and concern about the process of informing patients of positive results. ${ }^{23}$

\section{Conclusion}

Syphilis is the great imitator with protean clinical presentations and therefore diagnosis requires a high index of clinical suspicion. This case series indicates that patients with syphilis may present with unexplained symptoms to a variety of specialists and diagnosis can be delayed due to a failure to consider the need for a sexual history or syphilis testing. A failure to diagnose syphilis can leave patients at risk of developing severe complications, including sight-threatening uveitis. Given the rapidly increasing incidence of syphilis in the UK, there is a pressing need to improve awareness and recognition of this treatable infection, encourage increased sexual history taking and comprehensive sexually transmitted infection screening. 


\section{References}

1 Woolston SL, Dhanireddy S, Marrazzo J. Ocular syphilis: a clinical review. Curr Infect Dis Rep 2016; 18: 36.

2 Harman LE, Margo CE, Roetzheim RG. Uveitis: the collaborative diagnostic evaluation. Am Fam Physician 2014; 90: 711-6.

3 Ghanem KG, Workowski KA. Management of adult syphilis. Clin Infect Dis 2011; 53(Suppl 3): S110-28.

4 Janier M, Hegyi V, Dupin N et al. 2014 European guideline on the management of syphilis. J Eur Acad Dermatol Venereol 2014; 28 : 1581-93.

5 Kingston M, French P, Higgins S et al. UK national guidelines on the management of syphilis 2015. Int J STD AIDS 2016; 27: 421-46.

6 Oliver SE, Aubin M, Atwell L et al. Ocular Syphilis - Eight Jurisdictions, United States, 2014-2015. MMWR Morb Mortal Wkly Rep 2016; 65: 1185-8.

7 Public Health England. Health Protection Report: Infection Report. 2016. https://www.gov.uk/government/uploads/system/uploads/ attachment_data/file/559993/hpr2216_stis_CRRCTD4.pdf (accessed 4/5/17).

8 CDC. Clinical advisory: ocular syphilis in the United States. 2016. http://www.cdc.gov/std/syphilis/clinicaladvisoryos2015.htm (accessed 4/5/17).

9 Gass JD, Braunstein RA, Chenoweth RG. Acute syphilitic posterior placoid chorioretinitis. Ophthalmology 1990; 97: 1288-97.

10 Jabs DA, Nussenblatt RB, Rosenbaum JT. Standardization of uveitis nomenclature for reporting clinical data. Results of the First International Workshop. Am J Ophthalmol 2005; 140: 509-16.

11 Mathew RG, Goh BT, Westcott MC. British Ocular Syphilis Study (BOSS): 2-year national surveillance study of intraocular inflammation secondary to ocular syphilis. Invest Ophthalmol Vis Sci 2014; 55: 5394-400.

12 Eandi CM, Neri P, Adelman RA et al. Acute syphilitic posterior placoid chorioretinitis: report of a case series and comprehensive review of the literature. Retina 2012; 32: 1915-41.

13 Lee SY, Cheng V, Rodger D et al. Clinical and laboratory characteristics of ocular syphilis: a new face in the era of HIV co-infection. J Ophthalmic Inflamm Infect 2015; 5: 56.
14 Northey LC, Skalicky SE, Gurbaxani A et al. Syphilitic uveitis and optic neuritis in Sydney, Australia. Br J Ophthalmol 2015; 99: 1215-9.

15 Zhang R, Qian J, Guo J et al. Clinical manifestations and treatment outcomes of syphilitic uveitis in a Chinese population. J Ophthalmol 2016; 2016: 2797028.

16 Brook G, Bacon L, Evans C, McClean H et al. 2013 UK national guideline for consultations requiring sexual history taking. 2013; https://www.bashh.org/documents/Sexual History Guidelines 2013 final.pdf (accessed 4/5/17).

17 Tsimtsiou Z, Hatzimouratidis K, Nakopoulou E et al. Predictors of physicians involvement in addressing sexual health issues. J Sex Med 2006; 3: 583-8.

18 Trienekens SCM, van den Broek IV, Donker GA et al. Consultations for sexually transmitted infections in the general practice in the Netherlands: an opportunity to improve STI/HIV testing. BMJ Open 2013; 3(12): e003687.

19 Skingsley A, Yin Z, Kirwan P et al. HIV in the UK - Situation Report 2015: data to end 2014. 2015. https://www.gov.uk/government/ uploads/system/uploads/attachment_data/file/477702/HIV_in_ the_UK_2015_report.pdf (accessed 4/5/17).

20 Ellis S, Curtis H, Ong EL. HIV diagnoses and missed opportunities. Results of the British HIV Association (BHIVA) National Audit 2010. Clin Med 2012; 12: 430-4.

21 Deblonde J, Hamers FF, Callens S et al. HIV testing practices as reported by HIV-infected patients in four European countries. AIDS Care 2014; 26: 487-96.

22 Elmahdi R, Gerver SM, Gomez Guillen G et al. Low levels of HIV test coverage in clinical settings in the UK: a systematic review of adherence to 2008 guidelines. Sex Transm Infect 2014; 90: 11924.

23 Champenois K, Cousien A, Cuzin L et al. Missed opportunities for HIV testing in newly-HIV-diagnosed patients, a cross sectional study. BMC Infect Dis 2013; 13: 200.

24 Uveitis Information Group (Scotland). Glossary of Terms. 2007. https://uveitis.net/patient/glossary.php 